\title{
FLAG: the new Internet gateway to foreign law holdings in UK national and university libraries
}

\author{
by Peter Clinch
}

- Where can I locate in the UK the most extensive collection of the current legislation for the Cayman Islands?

- Which library has a comprehensive set of the World Trade Organisation International Trade Law Reports?

-Where can I find verbatim debates on bills as they pass through the New Zealand House of Representatives?

-Where are good collections of international environmental or commercial law?

-What are the opening hours and access conditions for a visiting researcher wishing to use the official publications collection of a particular major UK university?

$\mathrm{I}$ $f$ these are the types of question to which you sometimes require answers quickly, then a new Internet gateway will meet your needs. The Foreign Law Guide or FLAG project has developed an Internet database describing the holdings of foreign, international and comparative law in the national and university libraries of the United Kingdom. The database is free to use at: http://ials.sas.ac.uk/flag.htm

This short article describes the background to FLAG, the structure and content of the database and future developments.

\section{HOW DID FLAG DEVELOP?}

For many years the librarians of the five most extensive collections of foreign and international law in the United Kingdom (the Institute of Advanced Legal Studies (IALS) University of London; the School of Oriental and African Studies (SOAS) University of London; the Bodleian Law Library, University of Oxford; the Squire Law Library, University of Cambridge; and the British Library), have identified the need for some mechanism which would help them identify the strengths and weaknesses of their collections and allow them to create a coherent collection development strategy. The first step towards these goals would be to map the holdings of the five libraries.

In 1998 the government funded body the Research
Support Libraries Programme (RSLP) was formed with a budget over four years of 30 million pounds sterling to fund projects to meet similar aims. RSLP projects seek to bring together traditional and new forms of access to library information, with special reference to research support. The five libraries mentioned above prepared a bid, which went further than merely mapping their own holdings, and proposed the development of a national database including all major collections of foreign, international and comparative law in universities in the United Kingdom. The database would be the map upon which a national collection development strategy could be traced.

The bid was successful and FLAG is one of 16 collaborative collection management projects. They cover a wide range of subjects from archaeology to veterinary science. Some focus on describing holdings of publications from or about a particular part of the globe such as the Mapping Asia, Caribbean Studies and Russian and East European Studies projects, but FLAG is unique.

\section{WHY IS FLAG UNIQUE?}

FLAG is different from all of these projects and other collection description methodologies, such as conspectus, in a number of respects.

First, whilst FLAG employs the collection description 
template developed for RSLP by the United Kingdom Office for Library and Information Networking (UKOLN) based at Bath (see: http://www.ukoln.ac.uk/metadata/rslp) to structure the information recorded about each collection, it is doing so in a different way from other RSLP projects. Whilst most projects have created a single entry or, at the most, a handful of entries for each library, FLAG has collected data at an extremely fine grain level and created hundreds and, in some cases, thousands of collection descriptions for each library. Each FLAG entry for contributing libraries describes the holdings of one particular type of legal material for an individual country or international organisation. There is a well-established structure for the literature of law and lawyers frequently need to know where a particular type of legal material, such as codes or session laws or court reports, is held. The type of general collection description employed by other RSLP projects would be unhelpful to law users. So, FLAG has created a database where it is possible to search a hierarchy of descriptors of legal materials from the general (such as all types of publication containing legislation, to the specific: session laws only). Further, unique amongst RSLP projects, in the summer of 2000 , a postal and web survey of the potential users of the project database was conducted. Academics and law librarians were asked about their current information seeking habits when tracing foreign, international or comparative law, and their views on the content and search capabilities of the proposed database. The results of the survey, which yielded 111 responses from across the $\mathrm{UK}$, helped to inform the design and content of the database. A copy of the report of survey is available at the FLAG project web site.

Second, the FLAG project has adopted a rather different data collection methodology from other RSLP projects. Instead of collecting information for the database by means of a postal questionnaire addressed to contributing libraries, the FLAG Project Manager has personally visited each contributing library and collected information first hand at the shelves, or where this is not possible, from catalogues and acquisition records. In summer 2001 a postal questionnaire was sent to over 100 libraries in universities in the UK where law is taught to undergraduate level or above. About 35 university law libraries were identified as having significant holdings that should be included in the database. In addition, the survey included the Advocates' Library (part of the National Library of Scotland) and the National Library of Wales. Both these institutions have considerable collections of foreign and international law and have been included in the database. A copy of the survey results is available on the project web site.

Third, the FLAG project is highly focused in terms of the publications it covers: the primary law of countries outside England, Wales, Scotland and Northern Ireland and the publications of international organisations which create or are closely involved with law, excluding the European Union. FLAG excludes commentary: journals and textbooks. FLAG covers only paper and microform resources - electronic resources have been excluded because licence restrictions mean that electronic products are available only to the members of the institution paying the subscription. It is already clear that FLAG includes much material that is currently and never will be available in electronic format because of its age or specialised nature. Other RSLP projects have a more diffuse focus and attempt to briefly describe large, wide-ranging collections held in all formats.

Fourth, FLAG attempts to provide objective information about what is on the shelves of institutions in the UK. It provides numbers of titles or volumes. It makes no attempt to rate the strength of a collection by means of levels. FLAG quantitatively maps what is there now.

\section{HOW DO I USE THE DATABASE?}

Visit the database using the URL given earlier in this article. There you will find three ways to search:

(i) a simple search of the collection descriptions;

(ii) a simple search for contact information about the contributing libraries; and

(iii) an advanced search covering specialised fields not included elsewhere.

Most users will find the information they commonly require by using either of the first two search routes.

To search for collections of law of a particular country select the name of a country from the list of over 200 mentioned in the word wheel adjacent to the search box. Alternatively, to search for collections of a particular international organisation select the name of one of over 60 international organisations from the appropriate word wheel. To search for collections on a topic use the free text search box to interrogate the whole database for international and comparative law topics. Having selected either a country, international organisation or topic, you can also select the type of material you wish to tracelegislation, court reports, parliamentary proceedings, etcand, if desired, select the region of the UK so that the database will trace holdings in libraries only located in that area. If your search is successful the database will return a results list with up to five collections listed on each screen. Click on the link in any collection listed and the database will display a full description of the material held, including the dates of holding, whether the items are official publications, the language, and whether new material is still actively acquired. Links to the web site of each contributing library provide information about access conditions.

\section{THE FUTURE OF FLAG}

So far the database contains over 10,000 entries describing collections in more than 50 libraries. It is 
hoped to obtain additional funding to extend the project after its close in July 2002, to appraise and add to the database collections outside academia and the national libraries. Such libraries include the Inns of Court, Government departments, the Public Record Office and major public libraries. Also, the project needs to move to a further phase envisaged by the project partner libraries: the use of the database to draw up a national collection development strategy for foreign, international and comparative law.

In addition, if funding can be obtained there are several additional databases that could be built, to aid interrogation of FLAG and foreign law research generally. First, a series of brief descriptions of the law literature of each country could be compiled, to assist users identify the types of legal material appropriate to their research needs and, second, a searchable, world list of citation abbreviations.

With the addition of these features, FLAG has the potential to become a major foreign law hub on the Internet, of value to law researchers not only in the UK but worldwide.

\title{
E-banking and authentication
}

\author{
by Stephen Mason
}

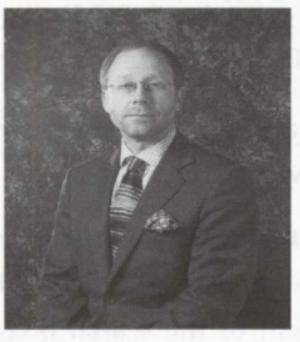

Steven Maso

$\Lambda$ uthentication is the process by which a person or legal entity seeks to verify the validity or genuineness of a particular piece of information. In certain circumstances, there is a need to verify the identity of an individual or legal entity. Discussions relating to authentication over the Internet have failed to grasp that a bank cannot verify the identity of an individual or legal entity over the Internet with any certainty. At best, a bank must put sufficient safeguards in place to reduce the risk of dealing with somebody other than their customer over the Internet.

\section{AUTHENTICATION FOR A PURPOSE}

It is not always necessary to establish the identity of a person or legal entity for a transaction to take place. Providing both parties to the barter are happy to buy and sell a product or service using a trusted means of exchange, both buyer and seller will part, comfortable that each has reached an amicable bargain. It may be that neither party to the trade will wish, or need, to meet again.

However, if something goes wrong with the transaction for any reason, one party may wish to pursue the other to
Peter Clinch

Project Manager, Foreign Law Guide (FLAG) Project

(Peter.Clinch@sas.ac.uk) resolve the matter. Depending on the nature of the dispute and what action the complaining party intends to take to seek a remedy, it may be necessary to establish the identity of the party causing the problem.

\section{An everyday example: validating the means of exchange}

When we deal directly with other people, the need to authenticate the identity of the other party depends on a number of factors, including the nature of the goods or services sold and any legal or regulatory requirements. Where there is no requirement or need to authenticate the identity of a person or legal entity, both the buyer and the seller assess the risk involved with the transaction. For instance, a buyer may decide to purchase a DVD on a Saturday market stall. If the buyer knows the trader from whom they intend to buy the DVD, a certain level of trust will already exist between the two. As a result, any transaction that takes place will be founded on mutual recognition and the knowledge by both parties that if something goes wrong, each knows how to contact the other to effect a remedy. 